\title{
2701. Torsional vibration analysis of crank train with low friction losses
}

\author{
Lubomír Drápal ${ }^{1}$, Pavel Novotný ${ }^{2}$ \\ Brno University of Technology, Brno, Czech Republic \\ ${ }^{1}$ Corresponding author \\ E-mail: 1drapal@fme.vutbr.cz, ${ }^{2}$ novotny.pa@fme.vutbr.cz \\ Received 25 October 2016; received in revised form 20 May 2017; accepted 27 May 2017 \\ DOI https://doi.org/10.21595/jve.2017.17876
}

Check for updates

\begin{abstract}
High level of mechanical efficiency is exacted from internal-combustion engines. The reduction of friction losses of crankshaft main bearings can significantly contribute to the enhancement of this efficiency. For this purpose, an innovative design of a crankshaft is developed. The potential of computational modelling during the development of this innovative crank train is described in the article. The dynamics of the whole crank train is solved by using a multi-body system software, where flexible finite-element bodies along with hydrodynamic bearings are incorporated. Regarding the simulation results, attention is paid to the torsional vibration and its analysis, including concept design of a torsional damper, because a reduction of friction losses is associated with the improvement of torsional vibration in this case.
\end{abstract}

Keywords: torsional vibration, torsional damper, crank train, crankshaft, multi-body system.

\section{Introduction}

Torsional vibration is common to internal-combustion engine crankshafts. The crank train generates alternating torque due to alternating combustion pressure in conjunction with the alternating effect of reciprocating parts inertia. This torque brings the elastic crankshaft in vibration about the axis of rotation. The torsional vibration can cause cracking and crankshaft failure; and therefore, this crankshaft loading is very dangerous.

A lot of effort has been made to simulate and measure the torsional vibration of the power train with the use of internal-combustion engines. Simulations focused only on this type of loading are often based on the so-called physical model of linear torsional vibration system, where all the rotating and the reciprocating parts are reduced to the crankshaft rotation axis, under the condition of potential energy and mean value of kinetic energy of the real system and also the physical model $[1,2]$.

A similar computational model can effectively be used also for the dynamics solution of the whole vehicle power train [3, 4].

The impact of a torsional damper, which is able to reduce the torsional vibration, can also be investigated by this physical model of torsional system utilizing discs, elastic and damping effects $[1,5,6]$, however it is possible to research the influence of a damper on the crank train by finite element analysis [7].

More complex computational models of internal-combustion engine dynamics, based on the Multi-Body System principles and containing flexible bodies, allow extensive analyses of engine vibrations, including the torsional vibration of the crank train [8].

Since the computational model should be verified by an experiment, rotational laser vibrometers are used for the measurement of the torsional vibration of some appropriate parts. The principles of the measurement are described in [9].

In this paper, torsional vibration is investigated in the case of innovative crank train of a 1.6 litre naturally aspirated spark-ignition engine. The engine has four cylinders in an in-line configuration and reduced friction losses. The reduction of crank train friction losses is achieved by a reduced number of crankshaft main bearings from 5 to 3 .

The new crankshaft with 3 main pins is derived from the standard one with 5 main pins mounted into the production engine. The missing main pins and adjacent crank webs are 
substituted with welded sheet-metal webs, which results in mass and inertia moments reduction, see Fig. 1, where pipes between crank pins enable a central feeding of crank bearings with lubricating oil.

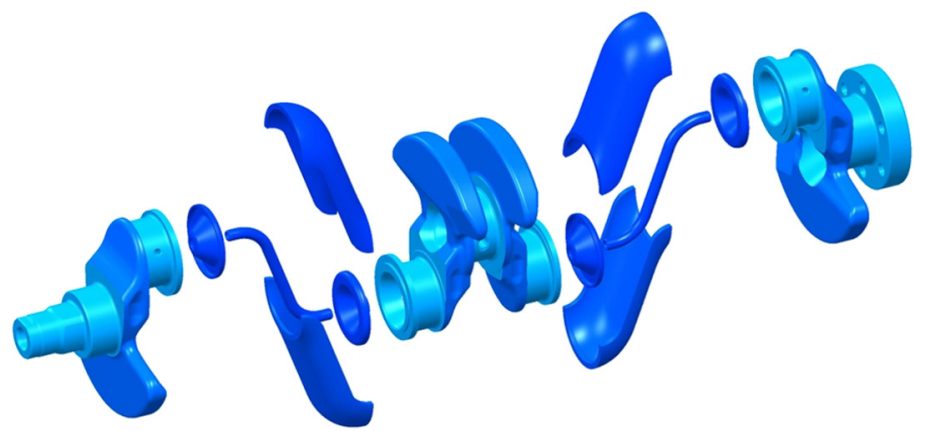

Fig. 1. An exploded view of the 3-main-bearing crankshaft

The sheet-metal web assemblies are laser welded with the flanges of crank pins, because laser welding brings low thermal loading of the weld, which was also experimentally validated during this project. Current design of the 3-main-bearing crankshaft results from previous design, computational, and technology studies $[10,11]$.

These studies show that potential for savings of power losses of crankshaft main bearing reaches around $33 \%$ for whole engine speed range and different load in comparison with the standard 5-main-bearing crankshaft. Simulations of crankshaft friction losses are validated also by measurement of motored standard engine with deactivated main bearing number 2 and 4 under miscellaneous lubricating oil conditions but under the same conditions for both variants.

Another advantage of the laser welded 3-main-bearing crankshaft is the lower mass - a reduction of slightly more than $12 \%$ - even though this crankshaft is made of steel, while the standard one is a ductile iron casting.

However not only friction losses and mass are affected by the new crankshaft design, but also changes in system dynamic response must be taken into account. Therefore the state-of-the-art computational methods are employed in order to investigate behavior of the crank train under dynamic conditions.

\section{Simulations of crank train dynamics}

For the solution of engine dynamics a complex computational model is used in the present study. The model is also known as a virtual engine and it is solved in time domain. This enables to involve various physical problems including different non-linear features.

The described computational model is assembled and solved in Multi-Body System (MBS) environment based on ADAMS programming language. During the assembly process of the model either ADAMS commands can be directly utilized or user-written FORTRAN or C++ subroutines can be incorporated $[8,11,12]$.

Since the virtual engine allows to solve the dynamics of the entire engine, similarly to real engines it includes all of its sub-systems. The included sub-system can be a crank train, a valve train, a timing drive, an oil pump, an auxiliary drive, a rubber damper and others. In order to analyze torsional vibration of the crank train, only the crank train module is utilized.

This module, Fig. 2, is composed of rigid bodies, flexible bodies and interconnections between them $[13,14]$.

As rigid are modeled those bodies whose deformation is not relevant for this type of simulation, nevertheless their inertia effects are considerable, therefore are defined by their location of center of gravity, mass, and inertia tensor. These bodies are:

- Piston group, 
- Connecting rod assembly,

- Dynamometer rotor.

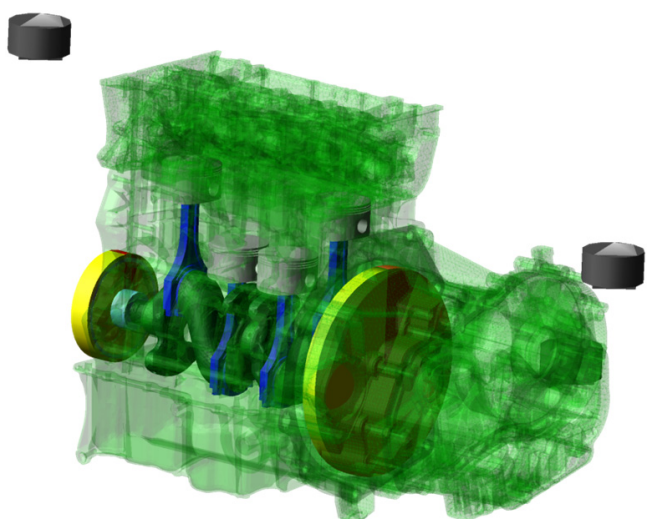

Fig. 2. The MBS computational model - the crank train as the main module of the virtual engine

The Craig-Bampton method is used for reducing the size of finite element models of these engine parts:

- Crankshaft,

- Flywheel,

- Crankshaft pulley,

- Crank train sump,

- Cylinder head,

- Engine block,

- Gear case.

Two rigid discs joint via a force element with torsional stiffness and damping represent a dumb-bell shaft connecting the flywheel with the dynamometer rotor (not shown in Fig. 2). The stiffness and damping values are adjusted on the basis of measurement of the whole crank train speed oscillation.

A non-linear hydrodynamic journal bearing model according to [15] is used for the interaction model between the crankshaft and the engine block and between the crankshaft and the connecting rod. The model contains the influence of oil grooves, while oil viscosity class SAE $5 \mathrm{~W}-30$ is considered during the simulation.

A general kinematic constraint is used for body which effect is important for dynamics of the system; however, which is not the subject matter of the simulation, for instance a constraint between a piston and a cylinder liner.

In order to excite the virtual engine, in-cylinder high-pressure measurement of the standard engine is carried out and results, after statistical processing according to [16], are used during the simulation. Simulation of the engine dynamics covers the whole operating speed range, thus from $1000 \mathrm{rpm}$ up to $6200 \mathrm{rpm}$.

\section{Torsional vibration}

A periodic signal of a quantity in time domain can be processed by the harmonic analysis in complex domain according to:

$Q_{c}=\frac{2}{n} \sum_{j=0}^{n-1} Q_{j} e^{i\left(k 2 \pi \frac{j}{n}\right)}$,

where $Q_{c}$ is a complex number associating amplitude and phase angle of the $k$ th harmonic order 
of quantity $Q_{j}$ defined in discrete time step $j$ for $n$ steps $[17,18]$.

Results of the signal processing obtained by this method at four-stroke engines contain also half-order harmonics $(4.5$ th, 5.5 th et cetera). This is caused by the fact that whole working cycle of a four-stroke internal-combustion engine takes two crankshaft revolutions $\left(720^{\circ}\right)$ while the fundamental frequency for engine dynamics is crankshaft rotational frequency $\left(360^{\circ}\right)$ [11]. Thus:

$\kappa=\frac{k}{2}$

where $\kappa$ is harmonic order regarding engine speed. This is illustrated by harmonic analysis in time domain in Fig. 3, showing the amplitude, the phase angle, and the multiple of fundamental frequency for first few harmonic components of a cylinder unit torque including effects of gas and inertia forces.

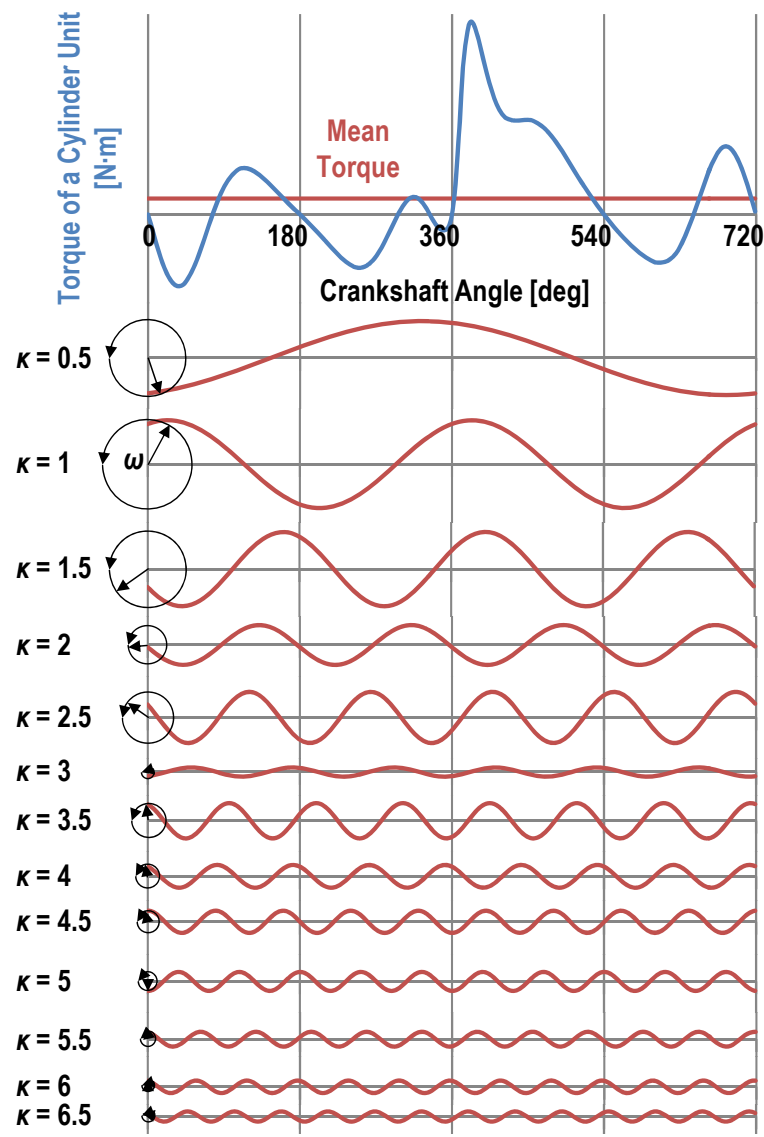

Fig. 3. Harmonic analysis of torque of a cylinder unit in time domain

The crankshaft pulley angular displacement is chosen for description and comparison of the crank train torsional vibration due to its complexity, the crank train speed oscillation and crankshaft torsional static and alternating deformation are therefore included into this quantity.

The computational model of the crank train dynamics is verified by means of experiment on an engine with the standard crankshaft. The crankshaft pulley angular displacement is measured by rotational laser vibrometer POLYTEC 4000 Series, and the comparison of the experiment and the simulation results is shown in Fig. 4. 


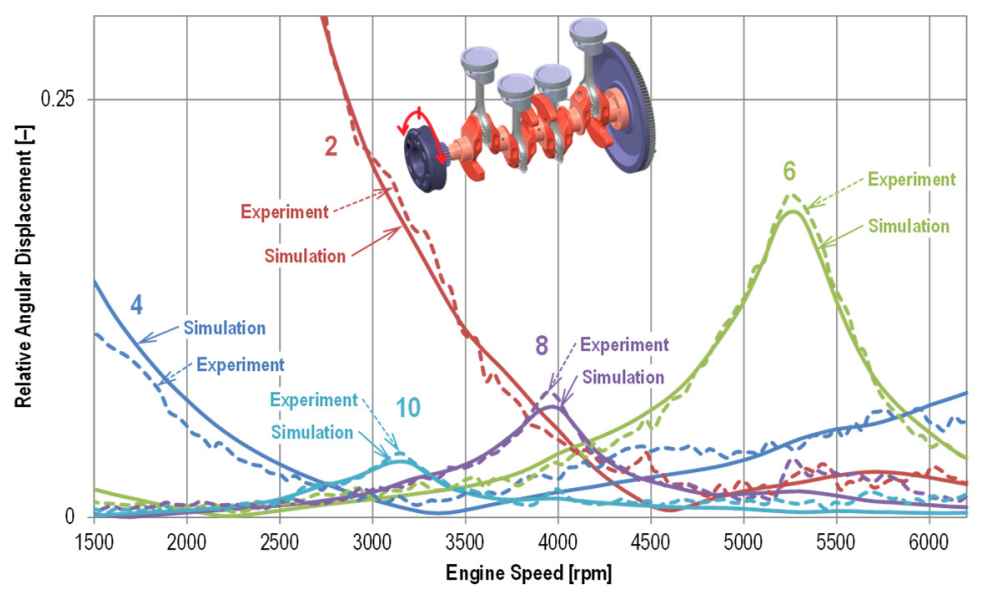

Fig. 4. Validation of the MBS model - harmonic analysis of the angular displacement of the standard crankshaft's pulley

Harmonic analysis of a crankshaft pulley angular displacement of the standard crank train obtained as a result of the simulation is shown in Fig. 5.

The 6th harmonic component takes a big share on crank train torsional vibration during its resonance reaching at $5250 \mathrm{rpm}$. The 8 th harmonic component achieves its resonance at $3900 \mathrm{rpm}$, however the resonance amplitude is smaller compared to the 6th one. The 10th harmonic component shows some resonance too, but its impact on the total shaft oscillation is considerably smaller. The mentioned harmonic components bring crankshaft on alternating torsional deformation while lower harmonic components, reflecting resonances at lower engine speed (the 2 nd one or the 4th one), show whole crank train speed oscillation - torsional vibration knot point lies between the flywheel and the dynamometer rotor.

The results of crank train dynamics simulation show that the so-called major orders take the highest part in crank train torsional vibration due to their identical phase angle at all cylinder units of the engine. For the studied in-line four-cylinder engine, these orders are integer multiples of 2. The synthesis of all harmonic orders corresponds to half of the peak-to-peak value from the periodic torsional oscillation.

The same dynamics simulation is carried out for crank train with 3-main-bearing crankshaft and results of harmonic analysis of the pulley's angular displacement are presented in the Fig. 6 . Significant changes in crankshaft design decrease the torsional natural frequency of the system.

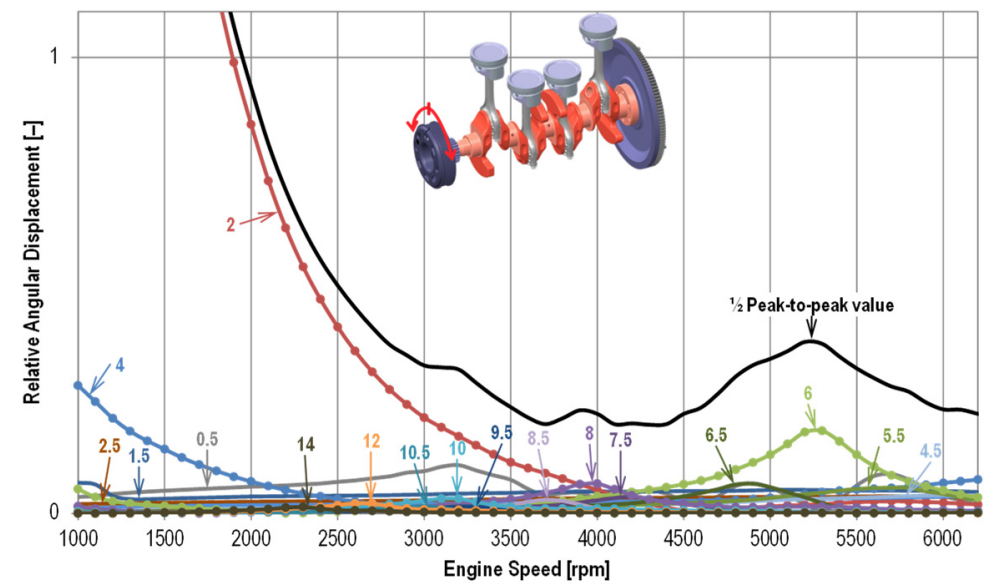

Fig. 5. Harmonic analysis of a pulley angular displacement of the standard crankshaft 


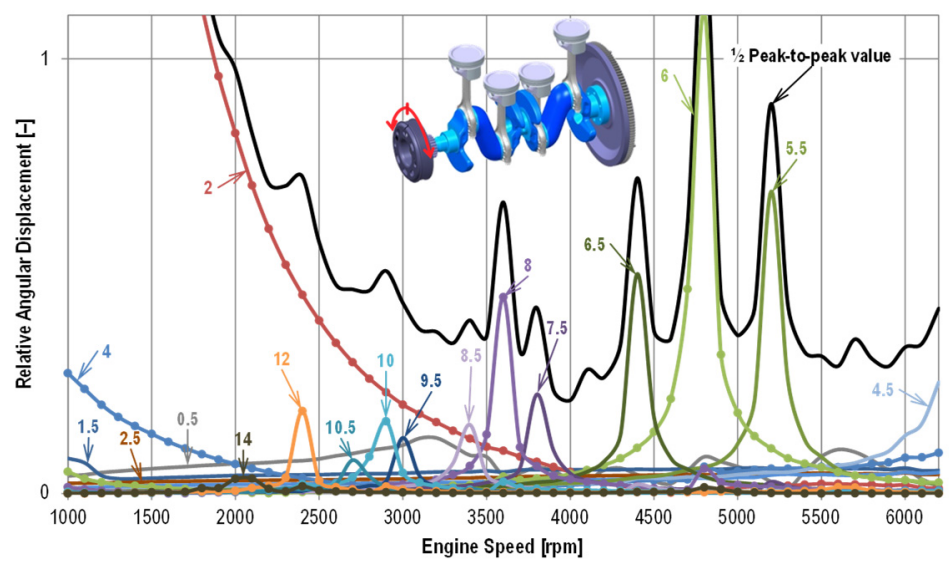

Fig. 6. Harmonic analysis of a pulley angular displacement of the new crankshaft

Lower natural torsional frequency can be noticed, for example, at resonance speed of the 8th harmonic component which is reached at $3600 \mathrm{rpm}$ (minus $300 \mathrm{rpm}$ as compared to the standard crank train). This is caused mainly by enlarged counterweighs of the new crankshaft significantly reducing load of the middle main bearing however also decreasing torsional natural frequency of the crank train.

Nevertheless, the small number of main bearings, where the crankshaft is supported by the engine block, brings further deviations in the crank train dynamics behavior. Amplitudes of the harmonic component resonances are significantly increased in the case of major harmonic orders and also other harmonic orders.

Crankshaft material has inherent damping determined by the experimental modal analysis for the need of simulation. However, as the simulation results show, "the sharpness" of resonance curves is caused, in particular, by the lower external damping of crank train torsional vibration by means of the crankshaft main bearings.

Shown torsional vibration of the new crankshaft, Fig. 6, cannot be admitted owing to likely crankshaft failure, which can be proved by only static structural analysis, if boundary conditions corresponding to the dynamic simulation are considered. Hence the next step for its reduction must be done.

\section{Concept design of a torsional vibration damper}

Engines of class as presented used to be equipped by a tuned rubber torsional vibration damper featured by good effect and low-costs [20]. The damper consists of a rubber band interposed between an inertia ring and a crankshaft pulley and its function, in sum, rests in retuning of the torsional system and putting more damping into it.

\subsection{Parameters of a torsional vibration damper}

For dimensioning of the damper, the equivalent moment of inertia of crank train must be determined. If the crank train is reduced into discrete discs jointed by immaterial elastic shaft, as shown in Fig. 6, the crank train equivalent moment of inertia can be calculated as:

$I_{e f}=\sum_{j=1}^{m} I_{j} a_{j}^{2}$,

where $a_{j}$ is the relative twist for appropriate natural frequency of the $j$ th disc having $I_{j}$ moment of inertia and the meaning of variables is further evident from Fig. 7. 


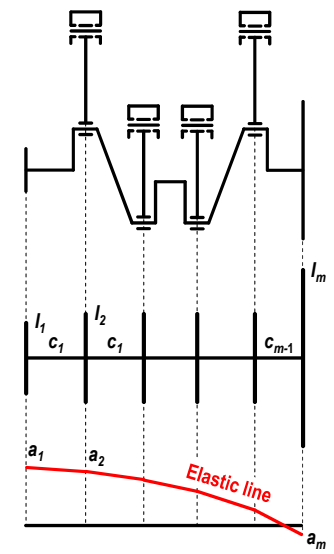

Fig. 7. The crank train discretization into individual discs and elastic line corresponding to the first natural frequency

In the case of the innovative crank train, the stiffness of elastic shaft sections, $c_{j}$, can be obtained by the finite element method if suitable boundary conditions are included [18].

Then relative size of the damper can be suggested as:

$\mu=\frac{I_{d}}{I_{e f}}$

where $I_{d}$ is moment of inertia of the damper inertia ring.

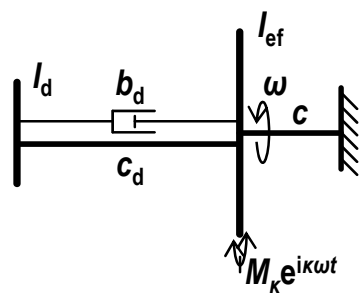

Fig. 8. A scheme of reduced crank train with a torsional damper

The damper relative tuning can be defined as:

$w=\frac{\Omega_{d}}{\Omega}=\frac{\sqrt{\frac{c_{d}}{I_{d}}}}{\sqrt{\frac{c}{I_{e f}}}}$,

where $\Omega$ is torsional natural frequency of the crank train, calculated via model described in Fig. 7 and verified by the virtual engine, $c$ is torsional stiffness according to Fig. $8, \Omega_{d}$ is torsional natural frequency of the damper and $c_{d}$ is torsional stiffness of the damper rubber band.

Relative damping is described by the ratio:

$\gamma=\frac{b_{d}}{2 I_{d} \Omega}$

where $b_{d}$ is rubber band viscous damping, limited by rubber material properties.

For initial parametric studies of damper should be defined also relative amplitude: 
$\xi=\frac{\varphi}{\varphi_{\text {stat }}}$

where $\varphi$ means dynamic amplitude of crankshaft pulley and $\varphi_{\text {stat }}$ is a static amplitude, and relative frequency:

$\eta=\frac{\omega}{\Omega}$

In which $\omega$ means excitation frequency.

According to Fig. 8, which describes torsional system including the reduced crank train and parallel model of torsional damper and with the use of parameters defined by Eqs. (4)-(8), the equation for relationship between relative amplitude and damper parameters can be derived:

$\xi=\sqrt{\frac{4 \gamma^{2} \eta^{2}+\left(\eta^{2}-w^{2}\right)^{2}}{4 \gamma^{2} \eta^{2}\left(1-\eta^{2}-\mu \eta^{2}\right)^{2}+\left[\mu w^{2} \eta^{2}-\left(\eta^{2}-1\right)\left(\eta^{2}-w^{2}\right)\right]^{2}}}$.

This equation allows to investigate the influence of damper relative parameters on the resonance curves of harmonic components of the crank train torsional vibration and is very useful for time-effective parametric studies.

Resonance curves, presented in Fig. 9, show the influence of damper relative size on relative amplitude for given relative tuning and the same damping ratio. The range of damper parameters, in practice, is limited by the build-up area, and material properties of a rubber band, especially the damping properties.

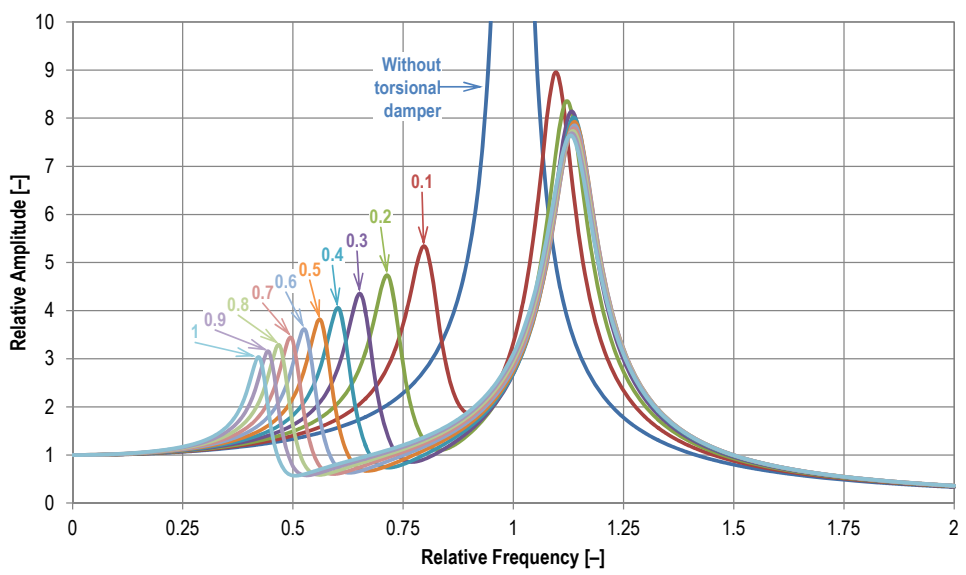

Fig. 9. Comparison of the torsional damper effect on resonance curve

\subsection{Effect of a torsional vibration damper}

The effect of the torsional vibration damper is verified by the virtual engine as well. Since real rubbers show hysteretic damping properties rather than viscous, Wiechert rheological model of a rubber band is used [21, 22].

The influence of the torsional vibration damper upon a crankshaft pulley torsional vibration is shown in Fig. 10 where the notes used mean:

- Without TD: the new crank train without the torsional damper,

- Standard TD: the new crank train with torsional damper intended for the standard crank train,

- Standard TD with softer rubber: the new crank train with torsional damper intended for the standard crank train but with lower torsional stiffness of the rubber band, 
- New torsional damper: the new crank train equipped with torsional damper with optimized parameters,

- Standard without TD: the standard crank train without a torsional damper.

Since the standard crank train can operate reliably without the use of a torsional damper (verified by a measurement), it is evident that the new crank train equipped by the optimized torsional damper should operate as well.

Because manufacturing of torsional vibration dampers is characterised by rubber properties variance, limits of rubber band stiffness are suggested and verified. A half peak-to-peak value of relative angular displacement of a crankshaft pulley for upper, lower, and nominal rubber band stiffness is shown in Fig. 11.

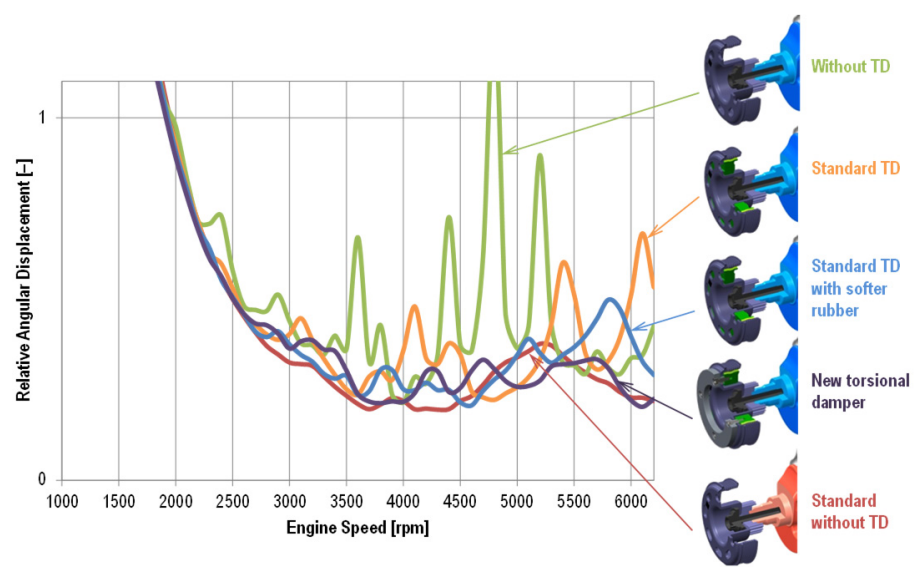

Fig. 10. Comparison of the torsional damper effect on a crankshaft pulley angular displacement ( $1 / 2$ peak-to-peak value)

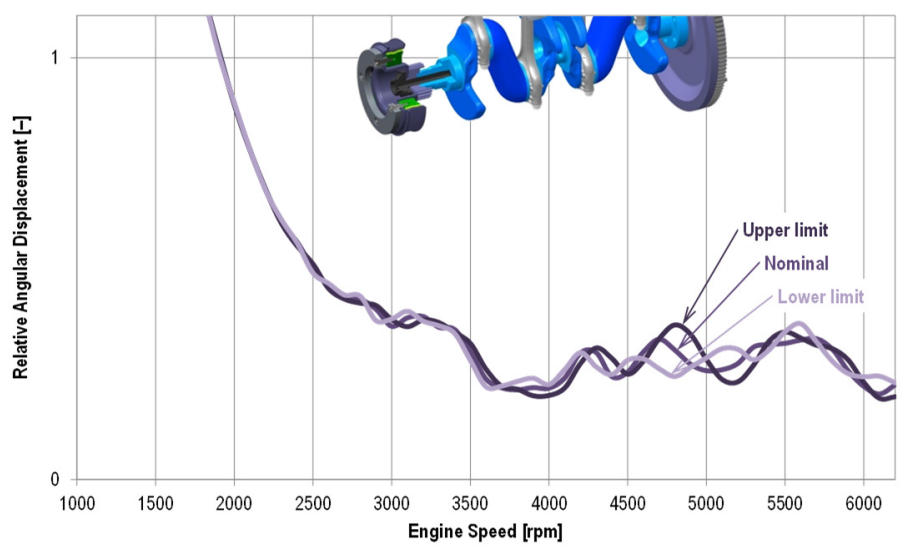

Fig. 11. The influence of rubber band stiffness limits upon a crankshaft pulley angular displacement ( $1 / 2$ peak-to-peak value)

\section{Conclusions}

Modern internal-combustion engines have to meet strict requirements on fuel efficiency which can be reached, among others, by low friction losses of a crank train. However, lowering of friction losses is often attached to the decline in system dynamic behavior. The described innovative crank train represents an extreme case of this behavior. Nevertheless, modern computational methods can bring solutions of the mentioned challenges and can shift manufacturing of expensive prototypes to later phase of the development process. 
Presented technique for analysis of a crank train torsional vibration and concept design of a torsional damper is universally applicable for general crank train of a two-stroke and a four-stroke engine.

Further steps of this project will be: a detail design of a torsional damper focused on temperature endurance of the rubber band, an analysis of crankshaft fatigue life, and a measurement of the real crank train prototype.

\section{Acknowledgement}

The research leading to these results has received funding from the MEYS under National Sustainability Programme I (Project LO1202).

\section{References}

[1] Filipović I., Bibić D., Blažević A., Milašinović A., Pecar A. Preliminary selection of basic parameters of different torsional vibration dampers intended for use in medium speed diesel engines. Transactions of Famena, Vol. 36, Issue 3, 2012, p. 79-88.

[2] Östman F., Toivonen H. T. Model-based torsional vibration control of internal combustion engines. IET Control Theory and Applications, Vol. 2, Issue 11, 2008, p. 1024-1032.

[3] Shengping F., Shengbo L., Ning L., Mishchenko E. Dynamic optimization of tracked vehicle power train based on torsional vibration analysis. Advances in Mechanical Engineering, Vol. 8, Issue 5, 2016, p. 1-12.

[4] Kučera P., Píštěk V. Longitudinal and lateral dynamics of a commercial vehicle in Simulink software. Proceedings of the International Conference on Transport Means, 2015, p. 458-461.

[5] Mendes A. S., Meirelles P. S., Zampieri D. E. Analysis of torsional vibration in internal combustion engines: Modelling and experimental validation. Proceedings of the Institution of Mechanical Engineers, Part K, Journal of Multi-body Dynamics, Vol. 222, Issue 2, 2008, p. 155-178.

[6] Matyja T., Lazarz B. Selection of torsional vibration damper based on the results of simulation. Journal of Vibroengineering, Vol. 17, Issue 8, 2015, p. 4069-4077.

[7] Wu F. T., Cheng C. C. Design and analysis of a speed-dependent torsional vibration absorber. Proceedings of the Institution of Mechanical Engineers, Part D, Journal of Automobile Engineering, Vol. 220, Issue 6, 2006, p. 763-774.

[8] Novotný P., Píśtěk V. New efficient methods for powertrain vibration analysis. Proceedings of the Institution of Mechanical Engineers, Part D, Journal of Automobile Engineering, Vol. 224, Issue 5, 2010, p. 611-629.

[9] Xiang L., Yang S., Gan C. Torsional vibration measurements on rotating shaft system using laser doppler vibrometer. Optics and Lasers in Engineering, Vol. 50, Issue 11, 2012, p. 1596-1601.

[10] Drápal L., Novotný P., Maršálek O., Raffai P., Píśtěk V. A conceptual study of cranktrain with low friction losses. Journal of Middle European Construction and Design of Cars, Vol. 11, Issue 2, 2013, p. 6-11.

[11] Drápal L., Novotný P., Píštěk V. Dynamic Simulation of Progressive Crank Train. Advances in Intelligent Systems and Computing Advanced Mechatronics Solution. Springer, Basel, 2016, p. 207-215.

[12] Novotný P. Virtual Engine - A Tool for Powertrain Development. Inaugural Dissertation, Brno University of Technology, Czech Republic, 2009.

[13] Rebbert M. Simulation der Kurbewellendynamik unter Berücksichtigung der hydrodynamischen Lagerung zur Lösung motorakusticher Fragen. Ph.D. Dissertation, Rheinisch-Westfälischen Technischen Hochschule, Aachen, Germany, 2000, p. 110.

[14] Ortjohann T., Rebbert M., Masssen F., Robers M. 3D-durability analysis of crankshaft via coupled dynamic simulation including modal reduction. SAE Technical Paper, 2006.

[15] Butenschön H. J. Das Hydrodynamische, Zylindrische Gleitlager Endlicher Breite Unter Instationärer Belastung. Ph.D. Dissertation, Universität Karlsruhe, Germany, p. 1976, p. 219.

[16] Heywood J. B. Internal Combustion Engine Fundamentals. 1st Edition. McGraw-Hill, New York, 1988, p. 930.

[17] Nestorides E. J. A Handbook on Torsional Vibration. Cambridge University Press, Cambridge, 1958, p. 664 . 
[18] Hafner K. E., Maass H. Torsionsschingungen in der Verbrennungs-kraftmaschine. Springer, Vienna, New York, 1985, p. 434.

[19] Craig R. R., Kurdila A. J. Fundamentals of Structural Dynamics. John Willey and Sons, New Jersey, 2006, p. 728.

[20] Heisler H. Advanced Engine Technology. 1st Edition, Arnold, Oxford Great Britain, 2002, p. 794.

[21] ADAMS/Engine Help. Version MD Adams R3. MSC. SOFTWARE, MSC Software Corporation, Newport Beach, CA, 2008.

[22] Brinson H. F., Brinson L. C. Polymer Engineering Science and Viscoelasticity: An Introduction. Second Edition, Springer, New York, 2015, p. 482.

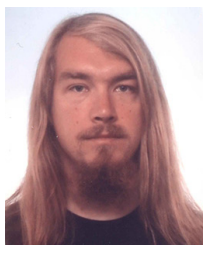

Lubomír Drápal works as a senior researcher at Institute of Automotive Engineering, Brno University of Technology, Czech Republic. His current research interests include computational modelling of dynamics and tribology of vehicle powertrains and its experimental validation.

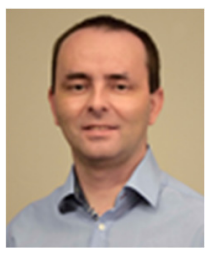

Pavel Novotný works at the Brno University of Technology as an Associate Professor. His research activities include development of new computational and experimental approaches for descriptions and solutions of the tribology, vibration and noise of powertrains or vehicles, including the subsequent transfer of knowledge into the industrial sector. 